University of Rhode Island

DigitalCommons@URI

2018

\title{
The Social Dynamics of Turbine Tourism and Recreation: Introducing a mixed-method approach to the study of the First U.S. Offshore Wind Farm
}

Hollie Smith

Tiffany Smythe

Amelia Moore

University of Rhode Island, ameliamoore@uri.edu

David Bidwell

University of Rhode Island, dbidwell@uri.edu

Jennifter McÇann

Follow this and addditional works at: https://digitalcommons.uri.edu/maf_facpubs

The University of Rhode Island Faculty have made this article openly available.

Please let us know how Open Access to this research benefits you.

This is a pre-publication author manuscript of the final, published article.

Terms of Use

This article is made available under the terms and conditions applicable towards Open Access

Policy Articles, as set forth in our Terms of Use.

\section{Citation/Publisher Attribution}

Smith, Hollie, et al. "The Social Dynamics of Turbine Tourism and Recreation: Introducing a mixed-method approach to the study of the First U.S. Offshore Wind Farm." Energy \& Research Social Science, vol. 45, 2018, pp. 307-317. http://dx.doi.org/10.1016/j.erss.2018.06.018

Available at: https://doi.org/10.1016/j.erss.2018.06.018

This Article is brought to you for free and open access by the Marine Affairs at DigitalCommons@URI. It has been accepted for inclusion in Marine Affairs Faculty Publications by an authorized administrator of DigitalCommons@URI. For more information, please contact digitalcommons-group@uri.edu. 


\title{
The Social Dynamics of Turbine Tourism and Recreation:
}

\section{Introducing a mixed-method approach to the study of the First U.S. Offshore Wind Farm}

Authors:

Hollie Smith, Assistant Professor of Environmental and Science Communication, University of Oregon

Tiffany Smythe, Assistant Professor of Maritime Policy, Strategy and Governance, United States Coast Guard Academy

Amelia Moore, Assistant Professor of Marine Affairs, University of Rhode Island

David Bidwell, Assistant Professor of Marine Affairs, University of Rhode Island

Jen McCann, Director of US Coastal Programs, Coastal Resources Center, and Director of Extension, Rhode Island Sea Grant College Program, University of Rhode Island

\begin{abstract}
Understanding the complex dynamics that influence energy transitions requires mixed methods and collaborations among researchers, resource managers, and communities. This essay details how an interdisciplinary team of researchers used a mixed-method approach to study the social dimensions of tourism and recreation as they relate to the first offshore wind farm in the United States, the Block Island Wind Farm. Although impacts to tourism from wind energy systems are widely cited as a concern by communities and policymakers, little work has sought to define what constitutes tourism and recreation impacts or provided empirical evidence of impacts from operating projects. Researchers adopted an iterative approach to research that combined discrete studies using media content analysis, ethnographic participant observation, and stakeholder focus groups, to understand the social effects of the wind farm on the tourism and recreation experience and the quality of life in Block Island and coastal Rhode Island. We detail key insights from our experimentation with an iterative mixed-method approach at Block Island and offer lessons for future studies using collaborative approaches to understand both the tangible and the intangible social dynamics of energy system transitions.
\end{abstract}

Keywords: Offshore wind; tourism; recreation; Block Island Wind Farm

\section{Introduction}

Offshore wind energy projects have grown significantly in the past decade. Europe is leading the offshore wind energy industry, with nearly $84 \%$ of all offshore wind installations being located off the coasts of eleven European countries at the end of 2017. Other countries, including China, Vietnam, Japan, and the United States, have been entering the market at a growing pace as offshore wind technology matures and investor confidence grows (GWEC, 2017). In the United States, offshore wind farms have been proposed along the US Eastern shoreline (United States Department of Energy, 2016), but these proposals have been met with mixed success, with several opponents to these developments often citing possible negative effects of turbines on 
coastal communities' tourism and recreation economies (Collins, 2017). As these projects grow, coastal communities across the globe will be faced with decisions about how to integrate the offshore wind industry into their economies, coastal land and seascapes, and cultures.

As this special issue aims to explore insights from how scholars design research on energy and climate change from a social perspective, we outline our direct experience studying the United States' first offshore wind farm, highlighting how our methods put empirical data and lived community experience and decision making into conversation with one another; These conversations offer important insight into how utilizing multiple, iterative methods in one study can create a more robust understanding of the tangible and intangible impacts of offshore wind on coastal communities, rather than a singular method or approach alone. Lessons learned from this project can be applied to the study of energy transitions in other tourism-dependent coastal communities both in the US and around the world, offering insight into how dynamics of place, geography, and economy, play a role in these transitions.

When an offshore wind energy project is proposed, people in communities near the proposed site and other interest groups frequently raise concerns that the project will affect tourism and recreation (Gee, 2010; Rudolph, 2014). Although there is often a presumption that wind energy projects threaten tourism (via visual impacts and resource-use conflicts), people also raise the potential of offshore wind farms acting as an asset to the tourism industry (Parsons \& Firestone, 2018). There is little empirical evidence for how wind energy projects have affected tourism and recreation; however, the literature suggests that wind farms may not negatively influence tourism to a substantial degree, and in fact, they may act as a minor attraction (Westerberg. Jacobsen, \& Lifran, 2013). With relative consistency, researchers have found that concerns about the visual impacts of offshore wind farms decrease as the distance of the wind farm from shore increases (Ladenburg, 2009; Lilley, Firestone, \& Kempton, 2010; Westerberg. Jacobsen, \& Lifran, 2013; Westerberg, Jacobsen, \& Lifran, 2015). Researchers further stress that tourists are not a singular group, and that their attitudes towards wind farms are influenced by personal factors, beliefs about renewable energy and the environment, and motivations for tourism and feelings about the landscape (Broekel \& Alfken, 2015; Ladenburg, 2009; Westerberg, Jacobsen, \& Lifran, 2015). There is also evidence that wind farms can attract tourists themselves or revitalize other tourism sectors (Albrecht et al. 2013; Firestone, Kempton, \& Krueger, 2008; Frantál \& Kunc, 2011; Frantál \& Urbánková, 2014).

Although impacts to tourism from wind energy systems are widely cited as a concern by communities and policy makers in the planning and permitting process, little work has sought to define what constitutes tourism and recreation impacts or to provide empirical evidence of impacts from operating projects. The approach we detail in this case study aims to fill that gap, while bringing together stakeholders and scholars from several disciplines. Specifically, we detail how we used an iterative mixed-method social science approach to 1) study the empirical 
and social effects of the United States' first offshore wind farm on the tourism and recreation experience and the quality of life in Block Island and coastal Rhode Island and 2) develop social indicators for use in Block Island and other future offshore wind farm settings. We provide a brief overview of current social science energy literature and the context of this study, detail our approach that integrates researchers and stakeholders through the use of content analysis, participant observation, and focus groups, and discuss key methodological lessons learned. Although complete results of this study will be reported in detail in elsewhere, throughout this article we will use two themes as examples of our findings in an effort to highlight how the combination of these methods offered insight that would have been obscured by a singular methodological approach.

\section{Current Trends in Social Science Energy Literature}

Energy systems are made up of an inherently complex set of connections between social, technological, and economic dynamics (Li \& Pye, 2018), yet in the past 20 years research has primarily focused on the economic and technical aspects of energy production, distribution, and regulation (Sovacool, 2014). In a meta-analysis of nearly 4500 articles on energy, Sovacool (2014) found that methods used skewed heavily towards the quantitative, with qualitative data collection occurring in less than thirteen percent of the articles. Moreover, among those articles using "human-centered" methods, few utilized common qualitative methods such as interviews and focus groups. In light of this gap, scholars have noted how incongruities between academic researchers, business persons, and policy makers can result in the lack of practical application for energy research (Sovacool, 2014). It has become clear that social scientists play a key role in parsing out the social dimensions of energy decisions that go far beyond the mere availability of technology or resources (Hui \& Walker, 2018; Bridge, 2018; Stephens, Wilson, \& Peterson, 2008), and that social science is crucial in identifying the positive and negative impacts and meaning of energy transitions on society (Stern, 2017; Butler, Parkhill, \& Luzecka, 2018; Benham, 2016). In response to this call for more social science in energy research, an increasing number of energy research studies are addressing human dimensions of energy systems, including the importance of place (Firestone, Bidwell, Gardner, and Knapp, 2018; DevineWright \& Howes, 2010; Hui \& Walker, 2018; Bridge, 2018), public engagement (Buhr \& Wibeck, 2014; Eaton et al, 2017; Klain et al, 2017), cultural narratives (Bidwell 2017; Malone et al., 2017; Harris, 2017; Smith et al, 2017; Moezzi, Janda, \& Rotmann, 2017), ethics (Smith \& High, 2017; Frigo, 2017; Howe \& Boyer, 2016), and social uncertainty (Li \& Pye, 2018; Purkus, Gawel, \& Thrän, 2017), among others.

The use of qualitative methods and diverse theoretical concepts is an important step forward, but still falls short on answering calls for increased interdisciplinarity and collaboration (Mallaband, Staddon, \& Wood, 2017; Pellegrino, \& Musy, 2017; Sovacool, 2014). Interdisciplinary approaches to energy research are particularly important, as energy development and transition is often characterized as a "wicked problem" that is multifaceted and embedded in complex 
ecological, economic, political, and cultural systems (Lemos \& Morehouse, 2005; Brown, Harris, \& Russel, 2010; Smith \& Lindenfeld, 2014). An interdisciplinary research design allows a research team to "simultaneously open new avenues of research and provide answers to [energy] questions that remain open" (Pellegrino \& Musy, 2017, p. 3). These team-based approaches aim to both integrate approaches from various disciplines and result in more usable science in the given context (Clark et al, 2011; Scott et al, 2009; Lemos \& Morehouse, 2005). The interdisciplinary team on this research project brings together scholars from sociocultural anthropology, sociology, communication, marine governance, and coastal resource management. The interdisciplinary nature of the research team allowed for a nuanced understanding of how tourism and recreation-based social dynamics and community experiences changed throughout the processes of planning, constructing, and operating the offshore wind farm.

Beyond interdisciplinary collaboration with the energy research community itself, there has been a shift in many scientific literatures to a stakeholder-inclusive approach ${ }^{1}$ (Pellegrino \& Musy, 2017). In studies of "wicked problems" like climate change and energy system transition, there has been a heightened importance placed on including stakeholders and decision makers, who might ultimately use or be affected by the science being produced, into the research process (Lemos \& Morehouse, 2005; van Kerkhoff \& Lebel, 2006; Clark et al, 2011; Cash, Borck, \& Patt, 2006; Shirk et al, 2012). The inclusion of stakeholders circumvents the notion that science will "trickle down and transfer" to society, end users, or decision makers (van Kerkhoff \& Lebel, 2006), and instead includes them in research design conversations from the beginning.

Pellegrino \& Musy (2017) argue the goal of this type of research is to "test the application of the theories and methods developed in concrete case studies founded in the real-world experience of stakeholders" (p. 2). This type of collaboration requires extra attention be paid to ways research methods are used and adapted, as they require constant "concept translations and switches from one mode of thinking to another" (Pellegrino \& Musy, 2017, p. 6). While this integrative approach brings multiple challenges, it also promises to open up new avenues for solving society's most pressing energy and climate problems (Lemos \& Morehouse, 2005).

\section{Research Context: The Block Island Wind Farm, Tourism, and Recreation}

The Block Island Wind Farm (BIWF) is a 30-megawatt, utility-scale offshore wind farm sited three miles southeast of Block Island, approximately fifteen miles off the coast of mainland Rhode Island, U.S. The concept of a Rhode Island wind farm was first introduced in 2006, and a private developer, Deepwater Wind, first proposed their Block Island project in 2008. During the planning and public comment period, citizens raised concerns over issues ranging from fisheries impacts to visual impacts to energy cost, but state and federal agencies determined the project would have no significant impact and approved project permits. The five-turbine project, the first

\footnotetext{
${ }^{1}$ We recognize the use of the term "stakeholder" is often power-laden and privileging, because not everyone in a community has the capacity to organize and be recognized as a formal stakeholder with interests in a given issue. We use the term in this manuscript for general ease of reading and consistency with the academic literature, but do so with hesitation and recognition of the power dynamics associated with this terminology.
} 
commercial offshore wind energy development in the United States, became operational in December 2016. Undersea cables deliver electricity generated by the turbines to the island and then to the mainland.

Within the United States, offshore wind energy projects have a range of socioeconomic and environmental effects on U.S. coastal communities, and the potential effects on recreation and tourism activities are particularly important to understand. Tourism and recreation are significant contributors to U.S. coastal communities and economies; in 2012, ocean-based tourism and recreation industries accounted for 2.1 million jobs and $\$ 45.7$ billion in wages in the U.S., representing $71.3 \%$ of total employment and $28.3 \%$ of the GDP of the U.S. ocean economy (NOAA, 2013). In Rhode Island, this industry accounted for $\$ 2.8$ billion in economic impact in 2013 (IHS, 2013). Tourism and recreation are widely considered growth industries, and recreational opportunities are a critical component to quality of life for residents of coastal regions. Finally, recreation and tourism activities may be uniquely affected - either positively or negatively - by the physical presence, public perception, and visual impacts of offshore wind farms, and studies in Europe and the U.S. have begun to explore this issue (e.g. Lilley, Firestone, \& Kempton, 2010; Westerberg, Jacobsen, \& Lifran, 2013). Place-based recreation and tourism is highly dependent on aesthetic and experiential considerations, and therefore any changes to land or seascape features may affect the success of tourism and recreation in a given area. Recreation and tourism can therefore represent one of the most logical and appropriate focus areas for evaluating the effects of offshore wind farms, especially in tourism-dependent locales.

The BIWF presents a rare and timely opportunity to evaluate the effects of offshore wind development on recreation and tourism in an iconic tourist landscape. Block Island is a uniquely popular New England tourist landscape, listed by The Nature Conservancy as one of the "Last Great Places," whose population swells from 1,000 to an estimated 15-20,000 every summer. Other Rhode Island south coast beaches and towns in sight of the wind farm, including Watch Hill and Newport, also support vibrant seasonal tourism economies. Rhode Island's marine recreation industries go hand in hand with coastal tourism: tourists from throughout the region travel to Rhode Island to engage in recreational boating, fishing and marine wildlife viewing. Our research team determined that the best way to understand the potential effects of offshore wind farms on recreation and tourism is to gather empirical data on the actual observed effects of the nation's first offshore wind farm on these activities in Rhode Island, and then use these data to develop social indicators for use in assessing the impacts of future offshore wind farm projects in other coastal tourist landscapes. In particular, our aim was to document empirical effects, like measurable changes in tourist activity and shifting dynamics within island residential and business communities. Throughout the remainder of this article, we will discuss preliminary study results around two themes that emerged throughout the research process to demonstrate the utility of our research design: 1) the undersea cable; and 2) the wind farm developing as a nascent tourist destination. 


\section{Research Approach}

This project was designed to bring together multiple researchers from the University of Rhode Island (URI), URI coastal resource managers, and people living and working on Block Island. While the general purpose of the project was to develop a precise understanding of the dynamics between an existing offshore wind farm and the regional tourism and recreation industry, the primary applied purpose was to produce a suite of indicators that would be useful for decision makers who are currently working with the BIWF and to decision makers in other places who might be interacting with offshore wind in the future. The research team adopted an interactive approach, with the assumption that usable solutions require the effort of multiple disciplines and the interaction with stakeholders (Lemos \& Morehouse, 2005; Agrawala, et al., 2001). This type of approach required funders, researchers, and stakeholders to interact at every stage of the research process (Scott, et al., 1999). And while the ultimate use of the end product will depend on a variety of factors that are outside the control of the research design/outcome itself, the researchers tried to fully commit to the components of interdisciplinarity and stakeholder participation in an effort to produce knowledge that is "demonstrably usable" (Lemos \& Morehouse, 2005, p. 66).

The URI team ${ }^{2}$ was formed through conversations about how we as scholars with shared research interests - energy systems in the Northeast and coastal tourism - could bring together diverse disciplinary approaches and concepts to study the Block Island Wind Farm, while responding to the practical and timely needs of local stakeholders and state and federal resource managers. The research design leverages two advantages unique to the research team: URI's proximity to Block Island and the Rhode Island south coast, and existing relationships between URI and the Rhode Island recreation and tourism industries. The URI team has deep local knowledge of these communities, and has previously worked closely with the region's recreation and tourism industries through the development coastal management initiatives. Our research was designed as a two-year project (2016-2018) through which we would directly engage visitors, representatives of key tourism and recreation sectors, and coastal residents affected by tourism to define and prioritize appropriate measures of offshore wind energy effects. This project was funded by the U.S. Bureau of Ocean Energy Management (BOEM), the federal government agency with responsibility for the leasing of offshore submerged lands and overseeing the responsible development of offshore wind energy.

The design also included formulation of a project advisory committee whose role was to provide the researchers with guidance and suggestions on research methods, data sources, and strategies for ensuring the project's relevance to practical management and community concerns. The project advisory committee consists of 18 researchers, practitioners, managers, and stakeholders.

\footnotetext{
${ }^{2}$ All researchers on this project were at the University of Rhode Island for the majority of this project's lifespan, being located in Kingston and Narragansett, RI, through the formative stages of this research.
} 
Researchers and practitioners involved include those with expertise in indicator development, tourism and recreation, or coastal planning and management. Managers include representatives of federal and state agencies; BOEM, the project funder, is also a management agency and participates in this group although they are not official advisory committee members.

Stakeholders include local residents as well as representatives of each of the tourism and recreation sectors, and include two tourism councils, a fishing charter boat captain, and a representative of the sailing community. In selecting advisory committee members, particularly those who are local stakeholders, the research team sought to ensure representation from all affected communities and all recreation and tourism sectors, and purposefully included some citizens who are not formally affiliated with local government or a trade association. It is important to note that no one advisory committee has held a position of greater power or influence with regard to this project than any other member, either formally or informally.

The advisory committee meets three times over the course of this two-year project. Meetings are held on dates and times that are convenient for as as many participants as possible, and options are provided for remote participation via phone or webinar. Each meeting has involved the presentation of elements of the research project followed by interactive discussion. The advisory committee has provided feedback and suggestions on research methods and potential data sources, and has reviewed and commented on draft research findings. In all cases, the team has used committee feedback and suggestions as a form of peer review, adopting some suggestions while retaining others for potential future projects since they were out of scope for this study's objective. Research team members have also engaged in informal ongoing dialogue with individual advisory committee members over the course of the project as appropriate to individuals' interest, availability, and subject matter expertise. For example, researchers sought suggestions from the tourism council directors on topics such as field locations for conducting PO, and all local stakeholder committee members were consulted directly for their suggestions of possible focus group participants. As project funder, BOEM has similarly provided suggestions and feedback throughout the project with the goal of ensuring that methods and results are presented in a way that is understandable, relevant, and useful to management agencies and local communities. The suggestions and feedback garnered through both the advisory committee and the project funder have helped the research team ensure that this project is methodologically rigorous, unbiased toward any one interest, and relevant and meaningful to managers and the local community.

The research, which will be complete in winter of 2018, incorporates three integrated studies using the methods of content analysis, participant observation, and focus groups in order to inform the development of social indicators. The design is iterative in nature, with researchers collaborating on research questions, design, and analysis for every phase of the project. This "reflexive iteration is at the heart of visiting and revisiting the data and connecting them with emerging insights, progressively leading to refined focus and understandings" (Srivastava \& 
Hopwood, 2009, p. 77). For example, the content analysis and/or participant observation could enable the research team to identify new themes, issue areas, or distinctions among the tourism and recreation sectors; the team would then have the opportunity to reshape one or more of the planned focus groups, and include the necessary discussion prompts, to best engage these sectors and address these issues. In another example, focus group discussions could result in the identification of new issues, areas, activities, or stakeholder groups to be focused on through subsequent participant observation. This "visiting and revisiting" of the data (Srivastava \& Hopwood, 2009) allowed for a more nuanced understanding of how different stakeholder experiences were intersecting and diverging. All of these elements feed into the development of social indicators, the culminating goal of this project (See Figure 1). This approach also allows for extensive and open-ended coordination between researchers leading their respective research tasks. In the following sections, we detail each method and how it has influenced the development of the project to date.

\section{Iterative, Integrative Nature of Research Design}

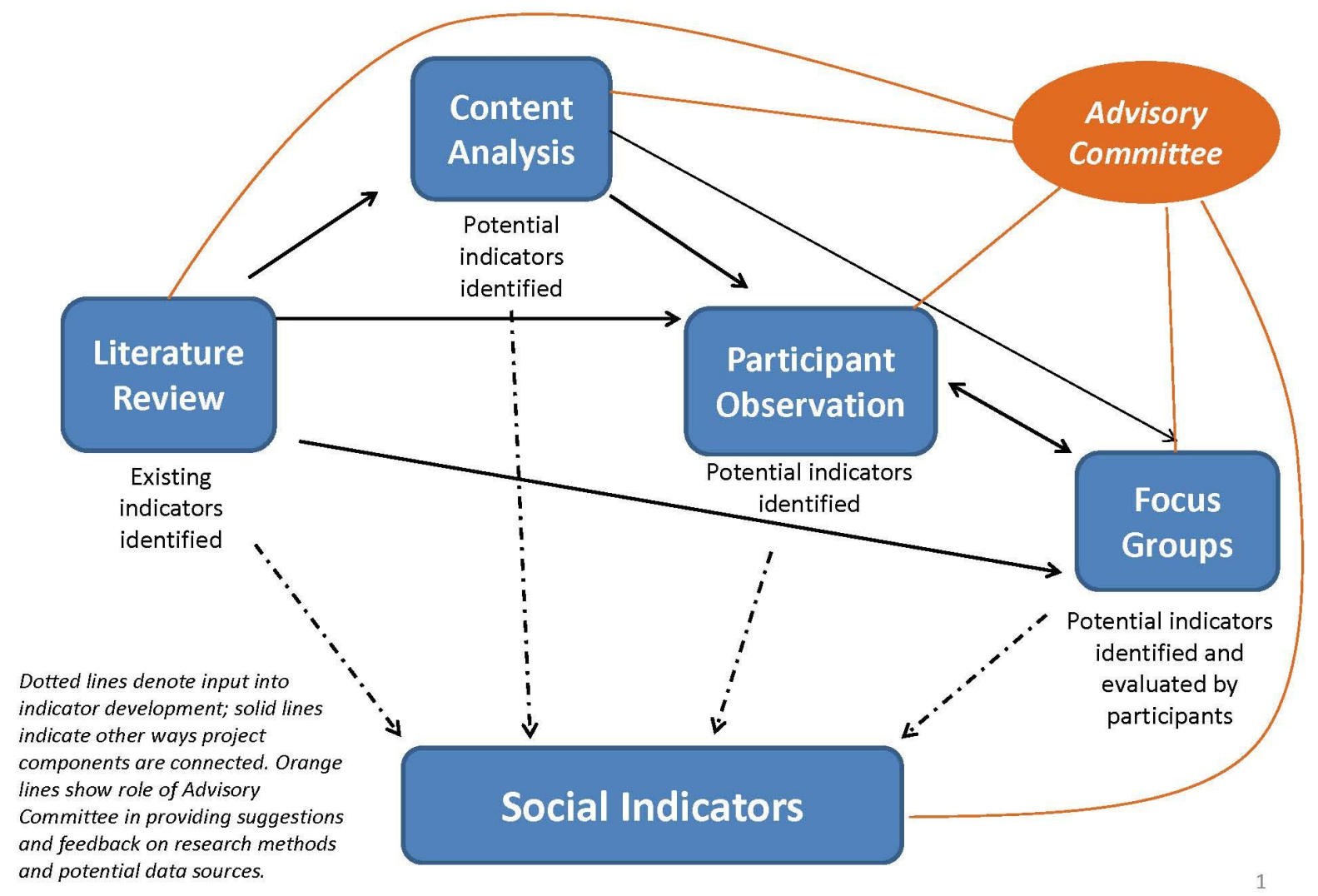

Figure 1. Overview of iterative research approach.

\section{Content Analysis}


Studying public discourse is a critical component for identifying indicators, as it reflects and influences social and political concern and/or support for environmental or government projects (Gamson \& Modigliani, 1989; McCombs, 2004). In regard to alternative energy development in particular, researchers have suggested understanding socio-cultural discourse is critical to comprehending deployment and success of wind power as well as deployment of other emerging energy technologies (Fischlein et al, 2010). As Stephens, Rand, and Melnick (2009, p. 172) note, "with respect to wind energy, the media clearly play a role in shaping people's understanding of the possible benefits and risks of the technology"; media may therefore play an important role in strengthening pro- or anti-wind movements (Thompson, 2005).

Given the importance of understanding public discourse, the research team used media archives to understand trends in public discourse since the BIWF was proposed. The data for the content analysis ranged from 2008, when Deepwater Wind proposed the first weather-monitoring tower to collect data for BIWF, to 2017, when the BIWF officially went live. Researchers included data from national, state, and regional news coverage of the BIWF. The research team relied heavily on The Block Island Times (BIT) archive as a primary resource for archival news data, as the BIT has kept a comprehensive archive of every story, both local and national, published about the BIWF. Researchers also collected data from all Rhode Island Department of Environmental Management and Coastal Resource Management Council's public hearings.

Researchers used thematic content analysis methods to identify the overarching issues related to BIWF, the relationship among them, and the patterns in their presentation (Creswell, 2012). Data analysis began with the process of open coding through which themes were derived and developed by looking through the data, with specific attention being paid to reasons for support and opposition to the BIWF. Researchers coded articles using NVivo, research software designed for large-scale data analysis projects, and Microsoft Excel. Two coders worked using a primary codebook developed throughout the open coding process (Riffe, Lacy, \& Fico, 1998).

Researchers added an additional level of coding once becoming familiar with the data, querying key words related to tourism and recreation.

Initial findings from the content analysis showed one of the most frequent media themes was concerns about the subsea transmission and fiber-optic cables and how this would affect life on Block Island. The transmission cable for energy and the fiber-optic cable were both being connected via the BIWF. The transmission cable brought the promise of steady delivery of energy to the island; The fiber-optic cable brought the promise of reliable and high speed internet. In the media discourse, discussions centered on when the fiber optic cable would be connected, how, and who would pay for it. The debates around the transmission cable highlighted primary drivers for community acceptance of the project: accessibility and stability. As a result, researchers asked about the cable in the focus groups and listened for mention of it in 
the participant observation, to see if the importance of the cable for energy provision and internet access was reiterated as a primary benefit to the community and reason for support.

Another initial finding from the content analysis was only revealed iteratively with the other project components. Surprisingly, the media content analysis showed a lack of direct mentions of tourism or recreation. After an initial low yield of tourism and recreation related themes, media researchers had conversations with the participant observation and focus group researchers, the Advisory Committee, and the project funder, to determine specific word queries to use that might yield more insightful data about tourism and recreation, even tangentially. As the overall focus of this project was to identify effects of the wind farm on tourism and recreation and develop indicators for future projects, the findings raised questions to be discussed in the next phases of research: Was the community not concerned about the possible impacts of the wind farm on tourism and recreation? Was the media just not reporting it? Were there higher priority issues related to the wind farm happening at the time and that's why those appeared more prevalent in the public discourse? These findings were presented to focus groups participants to stimulate discussion that brought possible new understanding as to why the wind farm and tourism were not explicitly linked in media coverage.

The strength of using content analysis in this type of research design is that it allows for an understanding of how an issue is presented to people who are not directly located in the area of the energy project itself - allowing for an understanding of why some projects might garner support or opposition from people not directly affected but in tune with the social discourse surrounding the project. The weakness of this type of method is that it lacks the granular insight into what the community itself was experiencing on the ground. Insofar as content analysis results provided relatively little insight into the concerns of recreation and tourism stakeholders on and around Block Island, these results underscored the importance of participatory research and focus groups as a means of obtaining stakeholder and industry expert input. The content analysis results also informed the participant observation by helping to identify initial fieldwork sites and by revealing other existing points of concern for the coastal community that became essential background for field observations.

\section{Participant Observation}

In order to produce qualitative information about perception, experience, power, enjoyment and intangible aspects of tourism and recreation, our team conducted ethnographic participant observation (PO) in the study area. PO can be a tool for the study of recreational sites, allowing the researcher to experience the tourist landscape in situ and in real time with visitors and residents. It is especially relevant as a tool in this case because of the possibility that the tourism experience itself may be directly affected by the physical presence of new energy infrastructure in a heavily used tourist landscape. PO is intended to provide insight into the relationship 
between tourists' and recreationalists' immediate experiences and relationships with wind farm infrastructure (Aitchison et al., 2000, Larkin, 2013, Stoffelen \& Vanneste, 2015).

PO is a tool for the study of sociocultural life and practices at the level of verbal and visible communication and phenomenological, embodied behavior (non-representational experience such as sensation) (Isen, 1987; Gregg \& Seigworth, 2010; McGrail, Davie-Kessler, \& Guffin, 2016), as well as a useful tool for social research with policy applications (Mastrofski, 1998; The State of Victoria, 2013; Yin, 1972), particularly for the study of tourism and recreation. These activities are based in dynamic practices that are often best accessed via qualitative methods (Macleod \& Carrier, 2010; Munsters \& Melkert, 2015; Smith, 1977; Stronza, 2001; Waitt \& Cook, 2007). PO is already used in the study of energy research (Smith \& High, 2017) and in the study of wind energy as a phenomenon with direct social impacts (Fraser, 2015; Howe, 2014).

The context of the BIWF determined PO site selection, along with sites identified through content analysis findings and discussions with the Advisory Committee. Because the BIWF can be seen from Block Island and mainland Rhode Island and there was concern expressed in the content analysis about visibility and effects for mainland Rhode Island, we covered both Block Island and mainland coastal recreational sites, as well as water-based recreational activities. During Year 1, five PO researchers worked alone or in small groups to document activities including recreational fishing, boating, whale watching, and charter tours within the vicinity of the BIWF. We visited public and private beaches, jetties, piers used for rod-and-reel fishing, and we observed bicycle and scooter tourists at scenic overlooks. We documented activities on ferry boats, at marinas, historical sites, and in seaside hotels. The majority of PO was conducted in the summer and shoulder seasons with winter sessions included for comparison. In summer, high traffic sites with strong wind farm views were visited frequently to account for changes in weather and tourism intensity over time.

Participation in tourism and recreational activities often requires engaging in light, open ended conversation with tourists in the field. Therefore, during PO sessions, we engaged a number of people in conversation, including visitors on Block Island beaches and the mainland coast, sightseers, recreational fishers and boaters, vacation home renters, boat operators, fishing and tour guides, marina operators, vendors, migrant workers, restaurateurs, rental home owners, and tourism decision makers in tourism councils and local government. In order to make these conversations relevant to the research, we utilized them as a form of very brief and casual semistructured interviews. We initiated discussions with a version of the simple question, "what is that?" when referring to the BIWF. When speaking with residents and members of the tourism industry, we would ask a version of, "how is your season going?"

PO methods included active listening and observation when participating in selected experiences. Data collection took the form of scratch notes on personal smartphones (to appear inconspicuous 
in the field), followed by compilation of field notes after the PO session was complete. Notes were compiled about site observations, informal conversations, observed discourse, enjoyment, and the physical experience of recreational activities. Photographs were utilized to help document behaviors (Bernard, 2006; DeWalt \& DeWalt, 2011; Kawulich, 2005), for example, recording how people engage with the wind farm by taking "selfies" with it in the background (in other words, taking pictures of people taking pictures). In the fall of Year 1, field interviews were conducted by the PO team, in coordination with the focus group team, with selected residents and members of the tourism industry to "compare notes" on the PO experience of the summer season vs. the industry experience and to clarify points of confusion about events researchers encountered.

Initial findings from PO reveal that the BIWF is in fact an appealing addition to the tourism and recreational features of the region for many of the observed seasonal visitors. For example, the offshore turbines now dominate the ocean views at a popular sea lookout site on Block Island, and the visitors that view this seascape for the first time are fascinated by the structures, asking many questions about them and attempting to take photographs of them. The turbines have become another point of interest on an island summer itinerary, like the Southeast Lighthouse, the Bluffs, and the "Indian Cemetery". From the sea surface, on ferry tours or charter boats, visitors and day recreators often gasp, point, and stare at the turbines as they approach them, impressed by the overwhelming scale of the industrial infrastructure. Common terms used to describe them are "gigantic" or "magnificent", and again, almost all visitors take photographs of them with their smartphones. However, from the mainland, the offshore wind farm is less distinctive, especially on hazy or overcast days, and many visitors to local beaches do not mention the turbines in the distance at all.

During Year 1 PO with business operators, in which researchers embedded themselves in shops, restaurants, and marinas, the team confirmed that interest in the transmission cable was as or more relevant to Block Islanders as the turbines were for visitors. Almost everyone observed eventually mentioned that the lack of reliable internet with enough bandwidth and the lack of stable energy was an issue for their business operations. Some people even considered the addition of broadband to be more important than the fact that the island was now powered by renewable energy. The fact that the fiber optic cable in the transmission line to the mainland is not yet connected to homes and businesses on Block Island, and is therefore still unable to provide broadband internet, remains a sticking point for many residents with an island-based business.

At the conclusion of Year 1, a summary of PO research results was shared with focus group participants to stimulate discussion and identify research needs for Year 2. Throughout Year 1, PO researchers met to discuss findings and integrate ideas with content analysis and focus group researchers to coordinate research design across project components. Year 2 PO will culminate 
in a Final PO Report summarizing the effects of the BIWF on tourism and recreation, identifying potential indicators, and providing social context for final indicators.

PO summaries will inform why observed groups react to the BIWF as well as how they react. This information will help determine which indicators would be the most relevant to stakeholders and resource managers. PO thus links concepts (like benefit and influence) with appropriate social indicators (like changes in enjoyment, behaviors, perceptions, and/or uses of space), based on an understanding of social context and the tourist landscape (Diedrich \& Garcia-Buades, 2009; Jorgensen, 1989; Rietbergen-McKracken \& Narayan, 1998).

The strength of using PO in this type of research is that it provides insight into the social meaning of tourist landscapes and experiences. And while PO is an excellent tool for understanding the more intangible and experiential aspects of social engagements with new energy infrastructure, one clear weakness is that it is not a useful tool for systematically assessing public opinion. There may indeed be a number of potential visitors who have chosen to avoid Block Island and Southern Rhode Island altogether due to the presence of the BIWF, and PO would not be able to access those people.

\section{Focus Groups}

While each of the data collection methods in this project stand on their own and contribute to the final development of tourism and recreation impact indicators, there is also a flow of research wherein one component informs another. Within the complete project design (Figure 1), the literature review and data collection methods of content analysis and participant observation flow towards the last stage of data collection, focus groups.

The strengths of the content analysis and participant observation components of the project are in identifying the anticipated and realized experiences of tourists, recreationalists, and the people who provide and manage those experiences. These methods rely heavily on the researcher as an instrument of organization and interpretation of data. With our focus on allowing the tourism sector in the study area to determine priorities for how benefits and impacts should be conceptualized and measured, focus groups play a critical role in the project. The focus groups most directly integrate stakeholders into knowledge production. The purpose of this method, in context of the larger project, is to continue to document experiences with the wind farm within the tourism and recreation community, but also to elicit responses to findings from the other research components and get feedback on potential indicators.

Kitzinger (1994) notes that focus groups are a particularly useful method for prioritizing respondent's worldviews and language above those of the researcher. The benefits of utilizing this method is that it is a cost-effective strategy for capturing multiple viewpoints and has been used in the study of wind energy projects to assess patterns of acceptance in energy landscapes 
(Scherhaufer, et al., 2017). Beyond the efficiency of reaching multiple stakeholders in a single data-collection session, however, focus groups have the added benefit of generating a different kind of data. Data are generated within a social context, as participants are able to construct responses based on what they hear from fellow participants, as well as reflect on points where they agree or disagree with peers (Fontana \& Frey, 1994; Kitzinger, 1994; Kitzinger \& Barbour, 1999; Patton, 2015). This interactive component makes focus groups more than simply a group interview, as it allows researchers to understand how particular themes resonate within a community. It does, however, raise challenges of facilitation, in order to ensure participation of all participants and avoid dominance of individual voices (Fontana \& Frey, 1994). Moreover, a lack of confidentiality inherent to group interaction, as well as group dynamics, also may reduce the frankness of participants' responses. In research projects concerning renewable energy and tourism, focus groups have been used to inform creation of contingent valuation and other surveys (Alvarez-Farizo \& Hanley, 2002; Ladenburg \& Dubgaard, 2007), while also providing more in-depth qualitative data to support integrated studies on place attachment and meanings of wind and wave energy projects (Devine-Wright \& Howes, 2010; Devine-Wright, 2011) and perception of community benefit components (Cass, Walker, \& Devine-Wright 2010). Further, focus groups have been used to either create or "short-list" locally relevant sustainability indicators (e.g. Reed et al. 2006; Reed et al. 2008).

In acknowledgement that tourism and recreation is not a monolithic sector, focus groups for this project were organized around categories of specific tourism and recreation activities being undertaken within the study area. Six groups were convened during the autumn of 2017 covering five sectors: recreational fishing, charter excursions, recreational boating and sailing, and landbased tourism on both Block Island and in nearby mainland coastal areas. Both the content analysis and the initial participant observation work informed the designation and subdivision of sectors. The homogeneity within groups was intended to facilitate a robust conversation, since participants would have a degree of shared knowledge and experiences. Focus group participants were identified and recruited by seeking suggestions from URI's existing regional contacts and from advisory committee members locally connected with these sectors, including many local trade associations or boards. Suggestions were sought for potential participants who would represent the full range and diversity of activities and users within each sector. For each sector, lists of potential participants were further refined by specific activity (for example, the landbased groups included vacation rentals and lodging, special event facilities, dining, beaches, and other outdoor recreation). Participants, 40 individuals in all, included official representatives of trade associations, facility operators and managers, and community members who were known for their leadership in particular recreation and tourism sectors. The focus groups varied in size and location, including two sessions on Block Island, in an effort to accommodate participants schedules.

Table 1: Description of tourism and recreation sectors used for organizing focus groups. 


\begin{tabular}{|l|l|}
\hline Sector & Description \\
\hline Boating/Sailing & $\begin{array}{l}\text { Includes private recreational boating, sailing, cruising, and racing } \\
\text { through independent activities or organized events in the study area. } \\
\text { Excludes fishing or charters of professionally operated vessels. }\end{array}$ \\
\hline Recreational Fishing & $\begin{array}{l}\text { Includes recreational fishing, or angling, activities taking place from } \\
\text { boats or ashore and on either private vessels or charter vessels in the } \\
\text { study area. Focus is on the anglers themselves, not on those running } \\
\text { fishing excursions professionally. }\end{array}$ \\
\hline Charter Excursions & $\begin{array}{l}\text { Includes for-hire charter or party boats, planes or helicopters offering } \\
\text { trips which may include fishing, wildlife viewing, or general } \\
\text { sightseeing. Focus is on those running the trips, not on the individual } \\
\text { anglers or passengers. }\end{array}$ \\
\hline Mainland & $\begin{array}{l}\text { Includes businesses and sites contributing to all land-based tourism } \\
\text { activities on Rhode Island's south coast in view of the wind farm, } \\
\text { including accommodations, beaches, activities, and popular } \\
\text { sightseeing destinations. Excludes fishing and boat-based activities. }\end{array}$ \\
\hline Block Island & $\begin{array}{l}\text { Includes businesses and sites contributing to all land-based tourism } \\
\text { activities on the island, including accommodations, beaches, } \\
\text { activities, and popular sightseeing destinations. Excludes fishing and } \\
\text { boat-based activities. }\end{array}$ \\
\hline
\end{tabular}

The research team developed a distinct set of topics and prompts to guide each focus group discussion for the first round of meetings, with the bulk of time given to group participants to share their experiences with the wind farm. Participants also received fact sheets summarizing the methods and key findings of the content analysis and first year of participant observations, with time given for them to reflect and discuss what was presented. Two members of the research team facilitated each of the focus group sessions, with student assistants taking notes. Sessions were audio recorded and transcribed for subsequent coding and analysis.

Discussions within the groups provided a depth to insights from other data collection techniques in this project. Common to the other methods, participants discussed both the undersea cable that connects the wind turbines to the island and the island to the mainland. In contrast to the findings of the content analysis and participant observation, this issue was not given much attention by the focus group participants. The primary concern was that unsubstantiated rumors about electric fields from the cable attracting sharks could have a negative effect on tourism activities if, as one participant put it, "that story gained legs." A more dominant theme, corroborating the participant observation findings, was that of the wind farm acting as an "attraction" for tourism and recreation activities. Early experiences on Block Island is that numerous tourists have expressed 
an interest in seeing the wind turbines and have visited sites specifically to view the wind farm. Because the best views of the wind farm are from traditionally popular tourist sites (such as a historic lighthouse), however, the wind farm more often serves as an additional feature for visitors. This is no more true than for charter excursions, where for-hire fishing boats and helicopter tours have added trips to the wind farm as a special addition to their offerings, often by requests from their clients. In some cases, such as days when fishing is poor, the wind farm provides a consolation experience; one charter boat captain explained, "It is like a tourist item, an attraction. We fish, but we go to the wind farms to get close to them, to look at them. People are interested in them. It has enhanced my business, that part of my business." Participants note that some visitors are quite interested in the technical aspects of the wind farm and actively seek information about its construction and how it functions.

To check the validity of the initial focus group analysis and get feedback on draft indicators, a second round of focus group meetings was held in Spring 2018. All of the first round participants were invited to attend one of three meetings (including one on Block Island), and a total of 18 participants attended these meetings. These meetings were valuable in clarifying some issues, but largely confirmed that the coding of the initial six sessions had captured the dominant themes expressed by the sectors. More importantly, these sessions helped refine the development of indicators, the final phase of our project.

\section{Integration}

In the final phase of this mixed-method project, we draw upon findings of the content analysis, participant observation, and focus groups to develop social indicators for use in understanding, measuring and monitoring the effects of the BIWF and other future offshore wind farms. Whereas some scholars have proposed indicators for monitoring offshore wind energy facilities and related infrastructure (e.g. Shiau \& Chuen-Yu, 2016), no such indicators or assessment framework have been developed to date based on empirical observations and experiences with U.S.-based offshore wind facilities. Further, contemporary public discourse about proposed U.S. offshore wind energy projects often includes concern about tourism and recreation impacts, such as in the recent case of a proposed wind farm off the coast of Ocean City, Maryland (Collins, 2017; Fritz, 2017), yet there is no existing framework, dataset, nor base of experience available to help U.S. stakeholders and decision-makers know what those precise impacts might be. Through our indicator development process, we are synthesizing data gathered through the research methods described above, and incorporating additional stakeholder and practitioner feedback, in order to develop an indicator framework that will fill both of these gaps.

Indicators are parameters whose measurements provide insight into a given phenomenon. Indicators guide decision-makers, stakeholders, and researchers in measuring and evaluating management issues and can also simplify and enhance communication regarding these issues. In recent years, social indicators have been used to assess marine issues including the vulnerability 
of fishing communities to regulatory and economic change (e.g. Colburn \& Jepson, 2012) and coastal communities' vulnerability to coastal hazards (e.g. Cutter et al., 2003). Social indicators have also been used to assess the social sustainability of energy technologies (Carrera \& Mack, 2010), including offshore wind farms (Shiau \& Chuen-Yu, 2016). Further, indicators have been developed to measure tourism and recreation within a sustainable development framework (Choi \& Sirakaya, 2006). In their UNESCO guidance document on coastal management indicators, Belfiore et al. (2003) list coastal tourism and recreation indicators including but not limited to: importance of tourism to the economy; tourist arrivals; tourist frequency during peak periods; trends in the use of the coastal zone in relation to economic value; number of parking spaces and associated income; number of hotels and similar facilities (and/or bed spaces); number of recreational amenities and opportunities; and intensity of use of recreational activity (land- and water-based). These examples illustrate how social indicators can include quantitative metrics which may utilize existing datasets (e.g. employment or number of visitors), but can also include qualitative metrics which may require additional social data collection and analysis (e.g. social and cultural values and experience).

A broad range of methodological approaches have been used to develop social indicators within the context of energy infrastructure, tourism and recreation, and sustainable development planning (Reed et al. 2006; Genskow \& Prokopy, 2009). Stakeholder input has been generally identified as an important input to indicator development in order to develop locally relevant indicators (Reed et al., 2006; Fraser et al., 2006). Methods such as content analysis (e.g. Jordan \& Javernick-Will, 2013) and focus groups (Reed et al. 2006; Reed et al. 2008) have been used in separate cases to inform indicator development, yet we have not identified another study that integrated our three methods of content analysis, participant observation, and focus groups into a social indicator development process.

Reed et al. (2006) examined the literature on developing and applying sustainability indicators and identified two methodological paradigms: the expert-led, top-down approach, and the community-based, bottom-up approach. Reed et al. then propose an adaptive learning process for indicator development integrating elements of both approaches, including community participation in addition to expert input. Our research builds upon this by using an iterative approach that allows for continual refinement of research methods, findings, and social indicators through stakeholder input (via focus groups) and suggestions and feedback from project advisory committee. In integrating both expert-led and stakeholder-driven approaches, our indicator development process (still under way) seeks to balance deductive and inductive approaches. For example, while our review of the scientific literature provided us with a range of general ideas for possible indicators, and helped shape our data collection approach, we have not limited ourselves to this list. Rather we are using our empirical data from the three different phases of data collection to generate a refined list of indicators that is shaped by our research 
findings and reflects the BIWF experience. As of this writing, the indicator development process is still under way, and will be detailed in a final report and forthcoming journal article.

Employing elements of the approach used by Kenney et al. (2016), our indicator development process began by developing a draft vision, or statement of purpose, for our indicators as well as a set of potential criteria for selecting final indicators. We then conducted an extensive literature review which included studies of the impacts of offshore wind farms elsewhere, studies of other types of energy infrastructure, studies of recreation and tourism, and other examples of indicators. From this review we identified a draft list of potential indicators as well as a potential framework for organization. Our potential indicators include both overarching and sectorspecific indicators (e.g. perceived community impact or benefit of project and changes in fishing or boating access around wind farm structures) and both quantitative and qualitative indicators (e.g. number of visitors to nearby iconic sightseeing location and quality of visitor experience at destination).

The research team's next step is to identify and incorporate other potential indicators based on findings from the content analysis, participant observation, and first round of focus groups. Themes that emerge from the content analysis, participant observation, and first round of focus groups through the coding process will be added to the indicators identified through the literature review, thus creating a comprehensive draft list of indicators. For example, perceived impacts or benefits of transmission cables has been added to our draft list of indicators based on content analysis and participant observation findings, as subsea transmission cable or fiber optic considerations were not on our initial literature-driven indicator list. The research team has also identified additional indicators from the Year 1 PO report and preliminary findings from the first round of focus groups that address the development on turbine tourism in the region.

Following this process, the team will assemble a complete draft list of indicators, which are being shared with stakeholders during the second round of focus group meetings. The research team will use focus group input to help refine the list of indicators and to prepare a final draft of indicators which will be shared with the project advisory committee for their review and suggestions. Our research experience to date reinforces the importance of focus group and advisory committee input, as well as researcher input, to selection of final indicators that are relevant, useful, and meaningful to the local community. This reflects the findings of Reed et al. (2006, p. 415) who found that "although [the identification of potential indicators] is often the domain of researchers and policy-makers, all relevant stakeholders must be included if locally relevant indicator lists are to be provided."

\section{Conclusion}

Overall, we found that integrating multiple methodological approaches while working with stakeholders and the funding agency allowed for a greater depth of inquiry compared to a 
monodisciplinary approach. The iterative approach, which required a high level of interaction among team members, was particularly useful for refining research protocols to be the most useful to the project and its goals. There was a high level of interaction among team members through emails, meetings, and in some cases through fieldwork and data collection - that allowed for real-time collaboration on all stages of the project and ample opportunity to "visit and revisit" the data (Srivastava and Hopwood, 2009, p. 77). We also found that the use of multiple methods allowed for triangulation of research findings and greater understanding of social dynamics that influenced the way we approach the social indicators that will be the final outcome of this project. While the methodological insights are the focus of this discussion, we find it equally important to highlight lessons from our research process as an interdisciplinary team. For ease of understanding, we break down our reflections in two parallel sections: 1) process insights and 2) methodological insights.

\section{Process Insights}

Successful collaborative research teams most often have diverse team members, place an importance on interpersonal skills (Cheruvelli et al, 2014), and have a shared vision for the project (Amey \& Brown, 2005; Hart \& Calhoun, 2010). This is particularly true of our team, as we have team members ranging from early to advanced-stage researchers and managers whose trainings span the disciplines of communication, anthropology, sociology and marine science. This dynamic required an ongoing conversation about and respect for how to divide work among the team and acknowledge each team member's contributions and disciplinary knowledge, while being open to changing approaches if something wasn't working. Team members worked to exhibit high levels of social sensitivity and emotional engagement (Cheruvelli et al, 2014; Woolley et al, 2010; Parker and Hacket, 2012) with one another throughout team meetings and through other means of communication. While these elements may sound insignificant, we have found that keeping lines of communication open through frequent emails, informal meetings, and shared writing projects among the team helped foster collaboration and disciplinary understanding within the team and our external partners. While each data collection process has operated individually, our willingness to talk to one another, try to understand how different research methods work and their value, and provide input on research questions has been very important for maintaining the project as a cohesive study. Another key factor to note in our team was the gender dynamic. Sovacool (2014) identified a significant gender imbalance in authorship in major energy journals, with only 16 percent of authors identifying as female. This is important to note in our particular case because four out of the five primary researchers on this project are female.

A unique aspect of our research team was the integration of faculty researchers with applied research and extension staff associated with the Rhode Island Sea Grant College Program. The team's Sea Grant research and outreach specialists have a history of working with the state's recreation and tourism industries and co-facilitated the state's Ocean Special Area Management 
Plan which helped site the wind farm. These team members' local knowledge and existing relationships with stakeholders enabled the research team to quickly develop communication with community members on Block Island and throughout the state's recreation and tourism sectors. Practical outcomes of these relationships include engaging key stakeholders on the project advisory committee, working closely with island tourism professionals to shape the Block Island components of the study, and ensuring the participation of recreation and tourism industry leaders in the sector-specific focus groups.

Rhode Island, and Block Island in particular, are very distinct case study sites. The small geographical nature of Block Island, where nearly everyone in the community knows one another, afforded us greater access to the various groups and interests on the island. Similarly, Rhode Island's marine recreation sectors are very small and concentrated geographically in just a few small communities and port areas. This allowed us the opportunity to ground-truth findings within these communities with greater ease than we may have had at different, more populated or dispersed sites. For example, we were asked to present this research project at a tourism council annual meeting and were able to engage with many community members who regularly attend such events on the island. Even given the unique context of the BIWF, we think there are key lessons learned in this approach that could be applied to diverse offshore wind settings in the future.

\section{Methodological Insights:}

One of the most interesting discussions that resulted from the research process was how to capture, measure, and write about intangible impacts of the wind farm. Throughout the research process, we grappled with measuring the intangible effects of transitioning to wind energy in an iconic coastal setting, including changes in social relationships to the land and seascape and in the quality of experience for residents and tourists on Block Island. While we did the initial literature review to understand how such impacts have been identified and utilized in other studies through a range of different methods, our study sought to understand how the community we are studying determined what constitutes a tourism and recreation impact. For example, in the focus groups, we asked stakeholder participants how they felt the wind farm had impacted recreation and tourism. Through this process, we identified tourism impacts AND benefits that we did not expect to find. One such example was the potential tourism impact of the undersea cable and tourists' beliefs that it attracted sharks to bathing beaches.

Several concepts that are difficult to quantify for use within an indicators framework, such as quality of experience and attachment to place, were central to discussions among the team throughout the project. Through the use of content analysis, we identified several of the key resident concerns about the economics and logistics of the wind farm -- how the wind farm would impact electricity rates and access to improved daily amenities like internet and cable -that we were able to explore through the subsequent methods. With participation observation, we saw how residents and visitors interacted with the physical turbines and how the turbines were 
incorporated into the tourist experience. Being able to observe people's interaction with the turbines allowed us to witness the subtle ways the turbines changed visitor experiences, from the information they sought to the photographs they took at specific PO sites. The final element of focus groups allowed for the ground-truthing of our observations, findings, and interpretations from the other forms of data collection. This is where we found it particularly helpful to facilitate conversations among the research team about the evolving meaning of the BIWF in the regional seascape and how our observations compared to focus group participants' experiences. The focus group discussions gave participants the opportunities to share observations and stories that changed the way we were thinking about particular issues. These discussions will provide a fertile foundation for subsequent focus group meetings through which we will refine and select social indicators.

The level of triangulation we have undertaken through this project has genuinely allowed us to develop a more nuanced understanding of how the community of and visitors to Block Island are experiencing the effects of the BIWF in different ways and at different points in the project's lifespan. Through this research design we have been able to parse out how different effects were or are still being felt more heavily in certain sectors and why certain effects mattered more to the community than others. There are two recommendations we can make from this experience: the use of the interactive, mixed methods research approach where participants have the opportunity to hear, comment on, and help researchers interpret data from the study, and the use of an advisory committee through the life of the project. These two elements were most influential in making our research truly iterative in nature and allowed for us as a research team to build trust within the community. Without the particular feedback from participants in the focus groups, findings from other elements of the study would have been a mere documentation of patterns, lacking understanding as to why we were seeing particular things and what meaning the findings might have. Giving community participants the ability to make meaning of the research allowed for a greater depth in the understanding of each distinct research phase findings, and how to more effectively use them in indicator development. In addition, having a diverse and welldeveloped group of stakeholders and experts working as an advisory committee throughout the life of the project gave the research team critical suggestions and feedback throughout the project development stages and facilitated access to community members involved in the focal recreation and tourism sectors that may not have happened otherwise.

The last critical element in our methodology that we would like to reflect on was the timeline in which our study is taking place. We received funding for this project in the year before the project went live, and have had the unique opportunity to do research before, during, and after the wind farm became operational. This was an invaluable opportunity to work with community members directly involved in this process and to watch their relationship to offshore wind evolve and unfold over three phases, from the information collected by content analysis in the planning and construction stages of the BIWF, to the in situ and experiential observations of PO during 
the first years of the wind farm's operation, to the targeted conversations and debates fostered by the focus group sessions after the first full tourist season in which the project was operational. Through this iterative process the team was able to gain a better understanding of the way in which a tourism-dependent community actively adapted to new energy infrastructure and reorganized their relationship to the seascape in terms of the reimagination of their seasonal tourism product and coastal economy. If this project had been funded a year later, we would have not had the unique opportunity to capture changes that signal both tangible and intangible effects on the Block Island community. From our experience, we would recommend taking this approach whenever possible to not only witness the impact of energy transition before or after it takes place, but throughout the entire process.

While we recognize that our case is unique in terms of geographic location, community dynamics, and well-established stakeholder relationships, we hope that the lessons learned can be applied to other locales going through energy transitions. We found it particularly useful to adopt an iterative approach, where we sought continuous suggestions and feedback from an advisory committee and community representatives. We believe the use of this approach can help us and other researchers gain a better understanding of the ways energy system transitions impact the social fabric of the communities in which they take place.

Acknowledgements: This research was funded by the U.S. Bureau of Ocean Energy Management, BOEM contract No. M16pc00016. The researchers wish to thank all of those who have given of their time and expertise as focus group participants or as members of the project advisory committee.

Disclaimer: The views expressed in this manuscript are those of the authors and do not represent the official policy or position of the U.S. Coast Guard, the Department of Homeland Security, the U.S. Bureau of Ocean Energy Management, the Department of Interior, or the U.S. Government.

\section{References}

Agrawala, S., Broad, K., Guston, D.H., 2001. Integrating climate forecasts and societal decision making: challenges to an emergent boundary organization. Science, Technology \& Human Values 26 (4), 454-477.

Aitchison, C, Macleod, N. E., \& Shaw, S. J. (2000). Leisure and Tourism Landscapes: Social and Cultural Geographies. New York, New York: Routledge.

Albrecht, C., Wagner, A., \& Wesselmann, K. (2013). The impact of offshore wind energy on tourism: Good practices and perspectives for the South Baltic Region. Report available at: 
http://www.offshorestiftung.com/60005/Uploaded/Offshore_Stiftung\%7C2013_04SBO_SOW_t ourism_st udy_final_web.pdf

Alverez-Farizo, B., \& Hanley, N. (2002). Using conjoint analysis to quantify public preferences over the environmental impacts of wind farms: An example from Spain. Energy Policy 30:107116.

Amey, M. J., \& Brown, D. F. (2005). Interdisciplinary collaboration and academic work: A case study of university-community partnership. New Directions for Teaching \& Learning, 102, 2335 .

Belfiore, S., Balgos, M., McLean, B., Galofre, J., Blaydes, M., \& Tesch, D. (2003). A Reference Guide on the Use of Indicators for Integrated Coastal Management. ICAM Dossier 1, I(OC Manuals and Guides No. 45. UNESCO 2003.

Benham, C. (2016). Change, opportunity, and grief: Understanding the complex socialecological impacts of Liquefied Natural Gas development in the Australian coastal zone. Energy Research and Social Science, 14, 61-70.

Bidwell, D. 2017. Ocean beliefs and support for an offshore wind energy project. Ocean and Coastal Management, 146:99-108.

Bernard, H. R. (2006). Research Methods in Anthropology: Qualitative and Quantitative Approaches. $4^{\text {th }}$ Edition. AltaMira Press.

Bridge, G. (2018). The map is not the territory: A sympathetic critique of energy research's spatial turn. Energy Research \& Social Science, 36, 11-20.

Broekel, T., \& Alfken, C. (2015). Gone with the wind? The impact of wind turbines on tourism demand. Energy Policy, 86, 506-519.

Brown, V. A., Harris, J. A., \& Russell, J. (2010). Tackling wicked problems through the transdisciplinary imagination. London: Earthscan.

Buhr, K., \& Wibeck, V. (2014). Communication approaches for carbon capture and storage: Underlying assumptions of limited versus extensive public engagement. Energy Research and Social Science, 3, 5-12.

Butler, C., Parkhill, K. A., \& Luzecka, P. (2018). Rethinking energy demand governance: Exploring impact beyond 'energy' policy. Energy Research and Social Science, 36, 70-78. 
Carrera, D.G. \& Mack, A. (2010). Sustainability assessment of energy technologies via social indicators: Results of a survey among European energy experts. Energy Policy 38: 1030-1039.

Cash, D. W., Borck, J. C., \& Patt, A. G. (2006). Countering the Loading-Dock Approach to Linking Science and Decision-making: Comparative Analysis of El Ni $\widetilde{A} \pm_{0} /$ Southern Oscillation (ENSO) Forecasting Systems. Science, Technology \& Human Values, 31(4), 465-494.

Cass, N., Walker, G., \& Devine-Wright, P. (2010). Good neighbors, public relations and bribes: The politics and perceptions of community benefit provision in renewable energy development in the UK. Journal of Environmental Policy and Planning 12:255-275.

Cheruvelil KS , Soranno PA, Weathers KC., Hanson, P. C., Goring, S. J., Filstrup, C. T., \& Read, E. K. (2014). Creating and maintaining high-performing collaborative research teams: the importance of diversity and interpersonal skills. Frontiers in Ecology \& the

Environment 12: 31-38.

Choi, H.C., \& Sirakaya, E. (2006). Sustainability indicators for managing community tourism. Tourism Management 27: 1274-1289.

Clark, W. C., Tomich, T. P., van Noordwijk, M., Guston, D., Catacutan, D., Dickson, N. M., et al. (2011). Boundary work for sustainable development: Natural resource management at the Consultative Group on International Agricultural Research (CGIAR). Proceedings of the National Academy of Sciences.

Colburn, L.L., \& Jepson, M. (2012). Social Indicators of Gentrification Pressure in Fishing Communities: A Context for Social Impact Assessment. Coastal Management 40: 289-300.

Collins, D. (2017). "Ocean City officials say wind turbines too close to coast an eyesore." WBAL-11 TV Baltimore. July 13, 2017. Online at http://www.wbaltv.com/article/ocean-cityofficials-say-wind-turbines-too-close-to-coast-an-eyesore/10302856.

Creswell, J. W. (2012). Qualitative Inquiry and Research Design: Choosing Among Five Approaches: SAGE Publications.

Cutter, S. L., Boruff, B. J., \& Shirley, W. L. (2003). Social Vulnerability to Environmental Hazards. Social Sciences Quarterly 84 (2): 242-261.

DeWalt, K. M., \& DeWalt, B. R. (2011). Participant Observation: A Guide for Fieldworkers. Rowan, AltaMira Press.

Devine-Wright, P. (2011). Enhancing local distinctiveness fosters public acceptance of tidal energy: A U.K. case study. Energy Policy 39:83-93. 
Devine-Wright, P., \& Howes, Y. (2010). Disruption to place attachment and the protection of restorative environments. Journal of Environmental Psychology 30:271-280.

Diedrich, A., \& Garcia-Buades, E. (2009). "Local Perceptions of Tourism as Indicators of Destination Decline." Tourism Management 30: 512-521.

Eaton, W. M., Burnham, M., Hinrichs, C. C., \& Selfa, T. (2017). Bioenergy experts and their imagined "obligatory publics" in the United States: Implications for public engagement and participation. Energy Research and Social Science, 25, 65-75.

Firestone, J., D. Bidwell, M. Gardner, and L. Knapp. 2018. Wind in the Sails or Choppy Seas?: People-Place Relations, Aesthetics and Public Support for the United States' First Offshore Wind Power Project. Energy Research \& Social Science, 40:232-243.

Firestone, J., Kempton, W., \& Krueger, A. (2008). Delaware opinion on offshore wind power. Final Report for DNREC, 2008; 1-60. Available at http://www.ceoe.udel.edu/windpower/docs/FinalDNRECOpinionReport.pdf

Firestone, J., \& Parsons, G. (2018). Atlantic offshore wind energy development: Values and implications for recreation and tourism. Sterling (VA): US Department of the Interior, Bureau of Ocean Energy Management. OCS Study BOEM 2018-013. 52 p. Available at https://www.boem.gov/espis/5/5662.pdf

Fischlein, M., Larson, J., Hall, D. M., Chaudhry, R., Rai Peterson, T., Stephens, J. C., \& Wilson, E. J. (2010). Policy stakeholders and deployment of wind power in the sub-national context: A comparison of four U.S. states. Energy Policy, 38(8), 4429-4439. doi:

http://dx.doi.org/10.1016/j.enpol.2010.03.073

Fontana, A. \& Frey, J.H. (1994). Interviewing: The art of science. Pp. 361-376 in Handbook of Qualitative Research. Edited by Denzin, N.K. \& Lincoln, Y.S. Thousand Oaks: Sage Publications.

Frantál, B., \& Kunc, J. (2011). Wind turbines in tourism landscapes: Czech Experience. Annals of Tourism Research, 38(2), 499-519.

Frantál, B., \& Urbánková, R. (2014). Energy tourism: An emerging field of study. Current Issues in Tourism, 1-18. 
Fraser, E.D.G., Dougill, A.J., Mabee, W., Reed, M., \& McAlpine, P. (2006). "Bottom up and top down: Analysis of participatory processes for sustainability indicator identification as a pathway to community empowerment and sustainable environmental management." Journal of Environmental Management 78: 114-127.

Fraser, R. (2015). "Blowing the Wind." Cambridge Interdisciplinary Research on the Environment: http://www.cire.group.cam.ac.uk/Blowinginthewind

Frigo, G. (2017). Energy ethics, homogenization, and hegemony: A reflection on the traditional energy paradigm. Energy Research and Social Science, 30, 7-17.

Fritz, J. (2017). "Proposed wind farm runs into opposition in Ocean City, Congress." The Baltimore Sun, July 21, 2017. Online at http://www.baltimoresun.com/news/maryland/politics/blog/bs-md-wind-farm-fight-20170721story.html.

Gamson, W. A., \& Modigliani, A. (1989). Media discourse and public opinion on Nuclear Power: A constructionist approach. American Journal of Sociology, 95(1), 1-37.

Gee, K. (2010). Offshore wind power development as affected by seascape values on the German North Sea coast. Land Use Policy, 27, 185-94.

Genskow, K. \& Prokopy, L.S. (2009). Lessons Learned in Developing Social Indicators for Regional Water Quality Management. Society and Natural Resources 23:1, 83-91.

Global Wind Energy Council. (2017). A snapshot of top wind markets in 2017: Offshore wind. Online at: http:/gwec.net/wp-content/uploads/2018/04/offshore.pdf

Gregg, M. \& Seigworth, G.J. (2010). The Affect Theory Reader. Duke University Press.

Harris, D. M. (2017). Telling the story of climate change: Geologic imagination, praxis, and policy. Energy Research and Social Science, 31, 179-183.

Hart, D. D., \& Calhoun, A. J. (2010). Rethinking the role of ecological research in the sustainable management of freshwater ecosystems. Freshwater Biology, 55(s1), 258-269.

Hui, A., \& Walker, G. (2018). Concepts and methodologies for a new relational geography of energy demand: Social practices, doing-places and setting. Energy Research \& Social Science, $36,21-29$. 
Howe, C. 2014. "Anthropocene Ecoauthority: The Winds of Oaxaca." Anthropological Quarterly 87(2): 381- 404.

Howe, Cymene \& Dominic Boyer. 2016. 'Aeolian Extractivism and Community Wind in Southern Mexico." Public Culture 28(2): 215-235.

IHS Consulting. (2013). Rhode Island Tourism 2013. Online at Http://Www.Discovernewport.Org/Documents/Industry-Resources/Ri-Tsa-2013-With-RegionalData.Pdf

Isen, A. M. (1987). "Positive Affect, Cognitive Process, and Social Behavior." Advances in Experimental Social Psychology 20. Leonard Burkowitz Ed. Academic Press Inc. p. 203-253.

Jordan, E., \& Javernick-Will, A. (2013). "Indicators of Community Recovery: Content Analysis and Delphi Approach." Natural Hazards Review 14: 21-28.

Jorgensen, D. L. (1989). Participant Observation: A Method for Human Studies. Sage Publications.

Kawulich, B. B. (2005). "Participant Observation as Data Collection Method." Forum: Qualitative Social Research 6(2), Art. 43.

Kenney, M.A., Janetos, A.C., \& Lough, G.C. (2016). Building an integrated U.S. National Climate Indicators System. Climatic Change 135: 85-96.

Kitzinger, J. (1994). The methodology of focus groups: The importance of interaction between research participants. Sociology of Health \& Illness 16:103-121.

Kitzinger, J., \& Barbour, R. (1999). Developing focus group research: Politics, theory and practice. Thousand Oaks, California: Sage.

Klain, S.C., Satterfield, T., MacDonald, S., Battista, N., \& Chan, K.M.A. (2017). Will communities "open-up" to offshore wind? Lessons learned from New England island in the United States. Energy Research \& Social Science, 34, 13-26.

Ladenburg, J. \& Dubgaard, A. (2007). Willingness to pay for reduced visual disamenities from offshore wind farms in Denmark. Energy Policy 35:4059-4071.

Ladenburg, J. (2009). Attitudes towards offshore wind farms-The role of beach visits on attitude and demographic and attitude relations. Energy Policy, 38, 1297-1304. 
Larkin, B. (2013). "The Poetics and Politics of Infrastructure." Annual Review of Anthropology 42: $327-343$.

Lemos, M. C., \& Morehouse, B. J. (2005). The co-production of science and policy in integrated climate Assessments. Global Environmental Change 15, 57-68.

Li, F. G. N., \& Pye, S. (2018). Uncertainty, politics, and technology: Expert perceptions on energy transitions in the United Kingdom. Energy Research \& Social Science, 37, 122-132.

Lilley, M. B., Firestone, J., \& Kempton, W. (2010). The effect of wind power installations on coastal tourism. Energies, 3, 1-22. Doi: 10.3390/en3010001

Macleod, D. \& Carrier, J. G. (2010). “Tourism, Power and Culture: Insights from Anthropology." In Tourism, Power and Culture: Anthropological Insights. Channel View Publications. P. 3-19.

Mallaband, B., Staddon, S., \& Wood, G. (2017). Crossing transdisciplinary boundaries within research: An 'on the ground' perspective from early career researchers. Energy Research \& Social Science, 26, 107-111.

Malone, E., Hultman, N. E., Anderson, K. L., \& Romeiro, V. (2017). Stories about ourselves: How national narratives influence the diffusion of large-scale energy technologies. Energy Research and Social Science, 31, 70-76.

Mastrofski, S. D., Parks, R.B., Reiss, Jr., A.J., Worden, R.E., DeJong, C., Snipes, J.B., \& Terrill, W. (1998). Systematic Observation of Public Police: Applying Field Research Methods to Policy Issues. National Institute of Justice Research Report.

McCombs, M. (2004). Setting the agenda: The mass media and public opinion. Malden, MA: Blackwell

McGrail, R., Davie-Kessler, J., \& Guffin, B. (2016). “Affect, Embodiment and Sense Perception." Cultural Anthropology: http://www.culanth.org/curated_collections/16-affectembodiment-and-sense-perception

Moezzi, M., Janda, K. B., \& Rotmann, S. (2017). Using stories, narratives, and storytelling in energy and climate change research. Energy Research \& Social Science, 31, 1-10. NOAA National Marine Fisheries Service. 2013. Fisheries Economics of the United States. Online at http://www.st.nmfs.noaa.gov/economics/publications/feus/FEUS2013/fisheries_economics_2013 
Parker, J. N., \& Hackett, E. J. (2012). Hot spots and hot moments in scientific collaborations and social movements. American Sociological Review, 77, 21-44.

Patton, M. Q. (2015). Qualitative research \& evaluation methods: Integrating theory and practice. Thousand Oaks, California: Sage.

Planning Decisions, Inc. 2014. Economic Impact \& Skills Gap Analysis. Prepared for the Rhode Island Marine Trades Association. Online at http://www.gwb.ri.gov/pdfs/RIMTAImpactRpt0914.pdf.

Pellegrino, M., \& Musy, M. (2017). Seven questions around interdisciplinarity in energy research. Energy Research \& Social Science, 32, 1-12.

Purkus, A., Gawel, E., \& Thrän, D. (2017). Addressing uncertainty in decarbonisation policy mixes -- Lessons learned from German and European bioenergy policy. Energy Research \& Social Science, 33, 82-94.

Reed, M.S., Fraser, E.D.G., \& Dougill, A. J. (2006). An adaptive learning process for developing and applying sustainability indicators with local communities. Ecological Economics 59: 406-418.

Reed, M.S., Dougill, A.J., \& Baker, T.R. (2008). Participatory indicator development: What can ecologists and local communities learn from each other? Ecological Applications 18(5): 12531269.

Rietbergen-McKracken, J., \& Narayan, D. (1998). Participation and Social Assessment: Tools and Techniques. The International Bank for Reconstruction and Development/The World Bank.

Riffe, D., Lacy, S., \& Fico, F. G. (1998). Analyzing media messages. Mahwah: New Jersey, Lawrence Erlbaum Associates, Inc.

Rudolph, D. (2014). Resurgent conflict between offshore wind farms and tourism: Underlying storylines. Scottish Geographical Journal, 130(3), 168-187.

Scherhaufer, P., Höltinger, S., Salak, B., Schauppenlehner, T., Schmidt, J., 2017. Patterns of acceptance and non-acceptance within energy landscapes: A case study on wind energy expansion in Austria. Energy Policy 109, 863-870.

Scott, A., Skea, J., Robinson, J., Shove, E., 1999. Designing 'interactive' environmental research for wider social relevance (Special Briefing no. 4). Economic and Social Research Council/Global Environmental Change Programme, Brighton, UK. 
Shiau, T. \& Chuen-Yu, J. (2016). Developing an indicator system for measuring the social sustainability of offshore wind power farms. Sustainability 8 (470): 1-14.

Shirk, J. L., H. L. Ballard, C. C. Wilderman, T. Phillips, A. Wiggins, R. Jordan, E. McCallie, M. Minarchek, B. V. Lewenstein, M. E. Krasny, and R. Bonney. 2012. Public participation in scientific research: a framework for deliberate design. Ecology and Society 17(2): 29. http://dx.doi.org/10.5751/ES-04705-170229

Smith, H., \& Lindenfeld, L. (2014). Integrating media studies of climate change into transdisciplinary research: Which direction should we be heading? Environmental Communication, 8(2), 179-196. doi: 10.1080/17524032.2014.906479

Smith, J., \& High., M. M. (2017). "Exploring the Anthropology of Energy: Ethnography, Energy, and Ethics." Energy Research and Social Science 30: 1-6.

Smith, J., Butler, R., Day, R. J., Goodbody, A. H., Llewellyn, D. H., Rohse, M., Smith, B. T., Tyszczuk, R. A., Udall, J., \& Whyte, N. M. (2017). Gathering around stories: Interdisciplinary experiments in support of energy system transitions. Energy Research and Social Science, 31, 284-294.

Smith, V. (1977). Hosts and Guests: The Anthropology of Tourism.

Sovacool, B.K. (2014). What are we doing here? Analyzing fifteen years of energy scholarship and proposing a social science research agenda. Energy Research \& Social Science 1:1-29.

Srivastava, P., \& Hopwood, N. (2009). A practical iterative framework for qualitative data analysis. International Journal of Qualitative Methods: 8(1), 76-84.

Stephens, J. C., Wilson, E. J., \& Peterson, T. R. (2008). Socio-Political Evaluation of Energy Deployment (SPEED): An integrated research framework analyzing energy technology deployment. Technological Forecasting and Social Change, 75(8), 1224-1246.

Stephens, J. C., Rand, G. M., \& Melnick, L. L. (2009). Wind energy in US media: a comparative state-level analysis of a critical climate change mitigation technology. Environmental Communication, 3(2), 168-190.

Stern, P.C. (2017). How can social science research become more influential in energy transitions? Energy Research \& Social Science 26:91-95. 
Stern, P.C., Sovacool, B.K., \& Dietz, T. (2016). Towards a science of climate and energy choices. Nature Climate Change 6:547-555.

Stoffelen, A., \& Vanneste, D. (2015). “An Integrative Geotourism Approach: Bridging Conflicts in Tourism Landscape Research." Tourism Geographies: An International Journal of Place, Space, and Environment 17(4): 544-560.

Stronza, A. (2001). "Anthropology of Tourism: Forging New Ground for Ecotourism and Other Alternatives." Annual Review of Anthropology 30: 261-283.

The State of Victoria. 2013. "Participant Observation." Effective Engagement. Department of Sustainability and Environment: http://www.dse.vic.gov.au/effective-engagement/toolkit/toolparticipant-observation

Thompson, R. (2005). Reporting offshore wind power: Are newspapers facilitating informed debate? Coastal Management, 33(3), 247-262.

U.S. Department of Energy \& Department of Interior (2016). National Offshore Wind Strategy. DOE/GO-102016-4866.

van Kerkhoff, L., \& Lebel, L. (2006). Linking knowledge and action for sustainable development. Annual Review of Environment \& Resources, 31(1), 445-477.

Waitt, G., \& Cook, L. (2007). "Leaving Nothing But Ripples on the Water: Performing Ecotourism Natures.” Social and Cultural Geography 8(4): 535-550.

Westerberg, V., Jacobsen, J. B., \& Lifran, R. (2013). The case for offshore wind farms, artificial reefs and sustainable tourism in the French Mediterranean. Tourism Management, 34, 172-183.

Westerberg, V., Jacobsen, J. B., \& Lifran, R. (2015). Offshore wind farms in Southern Europe Determining tourist preference and social acceptance. Energy Research \& Social Science, 10, 165-179.

Woolley AW, Chabris CF, Pentland A, Hashmi, N., \& Malone, T. W. (2010). Evidence for a collective intelligence factor in the performance of human groups. Science 330: 686-88.

Yin, R. K. (1972). Participant Observation and the Development of Urban Neighborhood Policy. Rand Corporation. 